\title{
DOES ANTICIPATED AGGREGATE DEMAND POLICY MATTER? FURTHER ECONOMETRIC EVIDENCE
}

Frederic S. Mishkin

Working Paper No. 789

\author{
NATIONAL BUREAU OF ECONOMIC RESEARCH \\ 1050 Massachusetts Avenue \\ Cambridge MA 02138 \\ October 1981
}

The research reported here is part of the NBER's research program in Economic Fluctuations. Any opinions expressed are those of the author and not those of the National Bureau of Economic Research. 
DOES ANTICIPATED AGGREGATE DEMAND POLICY MATTER?

FURTHER ECONOMETRIC EVIDENCE

\section{Abstract}

A heated debate has arisen over what Modigliani has dubbed the Macro Rational Expections (MRE) hypothesis. This hypothesis embodies two component hypotheses: 1) rational expectations and 2) short-run neutrality -i.e., that anticipated changes in aggregate demand will have already been taken into account in economic agents' behavior and will thus evoke no output or employment response. Together these component hypotheses imply that deterministic feedback policy rules will have no effect on business cycle fluctuations. The irrelevance of these types of policy rules is inconsistent with much previous macro theorizing as well as with the views of policymakers. It is thus an extremely controversial proposition which requires a wide range of empirical research.

This paper is a sequel to a previous paper by the author. That paper developed a methodology for testing the MRE hypothesis and found that anticipated money growth does matter to the business cycle. This paper extends the analyses to cases where the rate of nominal GNP growth or the inflation rate, rather than money growth, is the aggregate demand variable. The empirical results are also negative on the MRE hypothesis and its corresponding policy ineffectiveness proposition.

Frederic S. Mishkin Department of Economics 1126 East 59th St. University of Chicago Chicago, IL 60637

(312) 753-4518 


\section{INTRODUCTION}

A heated debate has arisen over what Modigliani has dubbed the Macro Rational Expectations (MRE) hypothesis. This hypothesis which is associated with the work of Robert Lucas, Thomas Sargent, and Neil Wallace, embodies two component hypotheses: 1) rational expectations and 2) short-run neutrality--i.e., that anticipated changes in aggregate demand will have already been taken into account in economic agent $s^{\prime}$ behavior and will thus evoke no output or employment response. Together these component hypotheses imply that deterministic feedback policy rules will have no effect on business cycle fluctuations. The irrelevance of these types of policy rules is inconsistent with much previous macro theorizing as well as with the views of policymakers. It is thus an extremely controversial proposition which requires a wide range of empirical research. 1

This paper is a sequel to a previous paper by the author. That paper developed a methodology for testing the MRE hypothesis and applied it to the case which has received the most attention, where money growth is the aggregate demand policy variable. However, other research has focused on cases where the rate of nominal GNP growth ${ }^{2}$ or the inflation rate, ${ }^{3}$ rather than money growth, is the aggregate demand variable. The results in these cases have been mixed in their support of the MRE hypothesis and further evidence seems necessary if we are to come closer to a resolution of the debate. This has led to this paper's empirical analysis of whether anticipated values of these aggregate demand variables matter. 


\section{THE METHODOLOGY}

The methodology for the empirical analysis to follow is only outlined briefly here. My earlier paper has a more extensive treatment of the methodology and the reader is referred there for more details.

The tests here are based on a model of the form

$$
y_{t}=y_{t}^{*}+\sum_{i=0}^{N} \beta_{i}\left(x_{t-i}-x_{t-i}^{e}\right)+\varepsilon_{t}
$$

where

$$
\begin{aligned}
& y_{t}=\text { unemployment or real output at time } t \\
& y_{t}^{*}=\text { natural level of unemployment or real output at time } t, \\
& x_{t}=\text { aggregate demand policy variable, either nominal GNP growth } \\
& x_{t}^{e}=\text { anticipated } x \text { conditional on information at time } t-1, \\
& B_{i}=\text { coefficients } \\
& \varepsilon_{t}=\text { error term. }
\end{aligned}
$$

Rational expectations implies that the anticipations of $x_{t}$ will be formed optimally, using all available information, and as is usual in this literature, models are assumed to be linear. A forecasting equation which can be used to generate these anticipations is

$$
x_{t}=z_{t} \gamma+u_{t}
$$

where

$$
\begin{aligned}
z_{t}= & \text { a vector of variables used to forecast } x_{t} \text { which are available } \\
& \text { at time } t-1, \\
r= & \text { a vector of coefficients } \\
u_{t}= & \text { an error term which is assumed to be uncorrelated with any } \\
& \text { information available at } t-1 \text { (which includes } z_{k, t} \text { or } u_{k, t-i} \\
& \text { for all } i 21 \text { and hence } u_{k, t} \text { is serially uncorrelated). }
\end{aligned}
$$


An optimal forecast for $x_{t}$ then simply involves taking expectations of equation (2) conditional on information available at $t-1$. Hence:

$$
x_{t}^{e}=z_{t} \gamma
$$

and substituting into equation (1), we have

$$
y_{t}=y_{t}^{*}+\sum_{i=0}^{N} \beta_{i}\left(x_{t-i}-z_{t-i} \gamma\right)+\varepsilon_{t}
$$

There are two identification problems that occur in the equation (4) model. Some assumption on the correlation of the error term, $\varepsilon$, and the right-hand side variables is necessary in order to identify the B-coefficients. The usual assumption, and the one that is used in the tests here as well as in previous empirical work on this subject, holds that all the right-hand side variables are exogenous and hence are uncorrelated with the error term. This assumption, that (4) is a true reduced form, implies that least squares estimation methods will yield consistent estimates of the $\beta^{\prime} s$.

The above assumption is more tenuous for the analysis in this paper than was true for previous work where money growth is taken as the aggregate demand policy variable. Although the exogeneity of money growth in output or unemployment equations is by no means uncontroversial, economists are more willing to assume the exogeneity of money growth than the exogeneity of nominal GNP growth or inflation in these equations. For this reason we must be more cautious in interpreting the results to follow. 4 However, they are of interest because they do confirm the previous findings with money growth and shed light on other evidence where nominal GNP growth and inflation are the aggregate demand variables.

The other identification problem has been raised by Sargent (1976b). If $\mathrm{z}_{t}$ includes only lagged values of $\mathrm{x}_{t}$ and there are no restrictions on the lag length $\mathrm{N}$, the model in (4) is observationally equivalent to "an unnatural 
rate model" where anticipated aggregate demand policy also matters. Hence, in this case we cannot distinguish between the two competing hypotheses discussed in this paper. This so-called observational equivalence problem has arisen in empirical work on whether anticipated aggregate demand policy matters, in particular that by Jean Grossman. Grossman analyzes the equation (4) model where the aggregate demand variable is nominal GNP growth. However, his forecasting equation includes only lags of nominal GNP growth as explanatory variables, so his model suffers from observational equivalence. 5 Thus Grossman's study contains little information on the question of whether anticipated aggregate demand policy matters.

The observational equivalence problem can be overcome, however--and it is in the tests of this paper--if $z_{t}$ includes lagged values of at least one other variable besides $x_{t}$ which does not enter equation (4) separately from the $B_{i}\left(x_{t-i}-z_{t-i} \gamma\right)$ terms. Now enough parameters of the equation are identified so that tests of the MRE hypothesis are feasible. A more extensive discussion of this issue can be found in Andrew Abel and the author and the reader is referred there for more details.

Estimation Issues

There are two methods that have been used to estimate the equation (4) model. Barro (1977) uses a two-step procedure where the forecasting equation (2) is estimated by ordinary least squares (OLS) over the sample period and the residuals from this regression are then used as the unanticipated aggregate demand variable in (4). Tests of the neutrality proposition then involve adding current and lagged values of the aggregate demand variable to (4) and testing with oLS the null hypothesis that their coefficients are equal to zero. 
Although this procedure generates consistent parameter estimates, it does not yield correct test statistics. It implicitly assumes that the covariance of the $\beta$ and $\gamma$ estimates are zero. When there are off-diagonal elements in the information matrix of the joint estimates, as there will be here, then ignoring them as in the two-step procedure leads to test statistics that do not have the correct asymptotic distributions. This can lead to inappropriate inference. As was shown in my earlier paper, if anything, the two-step procedure is biased against the MRE hypothesis.

A joint nonlinear estimation procedure discussed in more detail in my earlier paper avoids this problem by allowing for off-diagonal elements in the information matrix. It also produces more efficient parameter estimates because each equation makes use of information from the other in the estimation process. Another advantage is that it allows tests of both the neutrality and rationality implications of the MRE hypothesis, while the two-step procedure can test for neutrality only.

The joint nonlinear estimation procedure is used to estimate the (2) and (4) system, imposing the rationality constraint that $\gamma$ is equal in both equations. Non-linear least squares estimation proceeds here with the appropriate heteroscedasticity corrections discussed in my earlier work and the same identifying assumption that equation (4) is a true reduced form. 6

The (2) and (4) system and the MRE hypothesis embodies two sets of constraints. The neutrality proposition implies that output and unemployment deviations from their natural levels are not correlated with the anticipated movements in the aggregate demand variable. That is, $\delta_{i}=0$ for all $i$ in

$$
y_{t}=y_{t}^{*}+\sum_{i=0}^{N} \beta_{i}\left(x_{t-i}-x_{t-i}^{e}\right)+\sum_{i=0}^{N} \delta_{i} x_{t-i}^{e}+\varepsilon_{t} \text {. }
$$


Rationality of expectations implies that (5) can be rewritten as

$$
y_{t}=y_{t}^{*}+\sum_{i=0}^{N} \beta_{i}\left(x_{t-i}-z_{t-i} \gamma^{*}\right)+\sum_{i=0}^{N} \delta_{i} z_{t-i} \gamma^{*}+\varepsilon_{t}
$$

where $\gamma=\gamma^{*}$.

The joint test involves a likelihood ratio test for whether the (2) and (4) system satisfies the rationality constraints, $\gamma=\gamma^{*}$, and the neutrality constraints, $\delta_{i}=0$. This likelihood ratio statistic $-2 \log \left(L^{c} / L^{u}\right)$ is distributed asymptotically as $\chi^{2}(q)$ where

$q=$ is the number of constraints

$L^{C}=$ likelihood of the estimated constrained (2) and (4) system

$L^{u}=$ likelihood of the estimated unconstrained system, (2) and (6) where $\gamma=\gamma *$ is not imposed.

With the non-linear least squares estimation here it-equals ${ }^{7}$

$$
2 n\left[\log \left(S S R^{C}\right)-\log \left(S S R R^{u}\right)\right]
$$

where

$S S R^{C}=$ sum of squared residuals from the constrained system, $\mathrm{SSR}^{\mathrm{u}}=$ sum of squared residuals from the unconstrained system.

If the joint hypothesis of rationality and neutrality were rejected, we can obtain information on how much the rationality versus the neutrality constraints contribute to this rejection. A sensible nesting of the hypothesis testing proceeds as follows. The neutrality constraints are tested under the maintained hypothesis of rational expectations by constructing a likelihood ratio statistic as above where the constrained system is (2) and (4) while the unconstrained system is (2) and (6) again with the rationality constraints, $\gamma=\gamma^{*}$, imposed. A separate test for the rationality constraints proceeds similarly where the constrained system is (2) and (6) imposing $\gamma=\gamma^{*}$ and the unconstrained system is (2) and (6) where $\gamma=\gamma$ * is not imposed. 
In the models estimated here, the number of lags in the unemployment or output equations is so large that spurious rejections might occur because the small sample distributions of the test statistics differ substantially from the asymptotic distributions. In order to be certain that any rejections of the MRE hypothesis are valid, the models discussed in the text are estimated with the smoothness restriction that the coefficients of the unanticipated and anticipated aggregate demand variables lie along a fourth order polynomial with an endpoint constraint. This particular polynomial distributed lag (PDL) specification was chosen because it is rarely rejected by the data, ${ }^{8}$ it makes interpretation of the coefficients easier, and it has the advantage of using up few degrees of freedom. As the comparison of the text and Appendix II indicate, use of the PDL restriction leads to similar statistical inference on the validity of the MRE hypothesis, so we can be confident that there are no spurious rejections of the MRE hypothesis because of small sample bias. Granger and Newbold (1974) have pointed out the danger of conducting inference in a regression model where the serial correlation of the error term is ignored. To avoid this "spurious regression" phenomenon in the output and unemployment equations a correction for serial correlation is necessary that results in white noise residuals. Here the error term $\varepsilon$ of (4) and (6) is assumed to be a fourth-order AR process because fourth-order autoregressions are usually successful in eliminating serial correlation from quarterly, macro time series. This serial correlation correction is indeed successful in reducing the residuals to white noise. 9

\section{Specification Issues}

It is difficult on theoretical grounds to exclude any piece of information available at time $t-1$ as a useful predictor of a policy variable. Policymakers might react to this information even though there is no theoretical model that suggests that this should occur. Thus it might end up being a 
useful predictor of policy and should be included in the z-vector in (2). This reasoning suggests that an atheoretical statistical procedure based on the predictive content of information is the appropriate way to specify the variables belonging in the forecasting equation. ${ }^{10}$ The procedure used here and in my previous work amounts to running multivariate, Granger tests. The policy variable $x_{t}$, is regressed on its own four lagged values (again to insure white noise residuals) as well as on four lagged values of a wide ranging set of macro variables, such as: the quarterly M1 or M2 growth rate, the inflation rate, nominal GNP growth, the unemployment rate, the treasury bill rate, the growth rate of real government expenditure, the high employment surplus, the growth rate of the federal debt and the balance of payments on current account. ${ }^{11}$ The four lagged values of each of the variables are retained in the equation only if they are jointly significant at the five percent level. One advantage of this procedure is that it imposes discipline on the researcher that prevents his searching over forecasting equation specifications that lead to results confirming his priors.

Earlier research on the MRE hypothesis with an equation (4) model Ifor example, Robert Barro (1977, 1978), Robert Barro and Mark Rush, Jean Grossman and Leonardo Leiderman] has used a fairly short lag length--two years or less--on the anticipated and unanticipated $\mathrm{X}$ variables. This paper looks at longer lag lengths for two reasons. Experimenting with plausible, less restrictive models that have longer lag lengths is an appropriate strategy for analyzing the robustness of results because this only has the disadvantage of a potential decrease in the power of tests but will not result in incorrect test statistics. $^{12}$ In addition estimates in this paper and in Robert Gordon find that unanticipated aggregate demand variables lagged as 
far back as twenty quarters are significantly correlated with output and unemployment.

\section{THE RESULTS}

The estimated models in the text use seasonally adjusted, postwar quarterly data over the 1954-76 period and the methodology outlined in the previous section. The sample starts with the first quarter of 1954 because this was the earliest possible start date when models with long lags are estimated. The data are discussed in more detail in the data appendix. In pursuit of information on robustness, both output and unemployment models are estimated in this paper with nominal GNP growth and inflation as the aggregate demand variable. The natural level of unemployment or output, $y_{t}^{*}$, is estimated here as a simple time trend as in Barro (1978). A more complicated Barro (1977) specification has been avoided because, as is Indicated by David Small and Barro (1979), its validity is doubtful.

The first step in pursuing the MRE tests is to specify the variables entering the forecasting equations for nominal GNP growth and inflation. The multivariate, Granger procedure outlined in the previous section yields the following specifications.

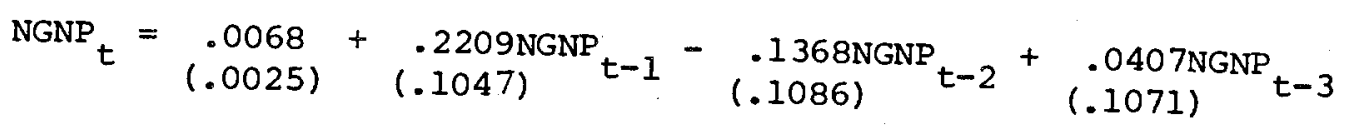

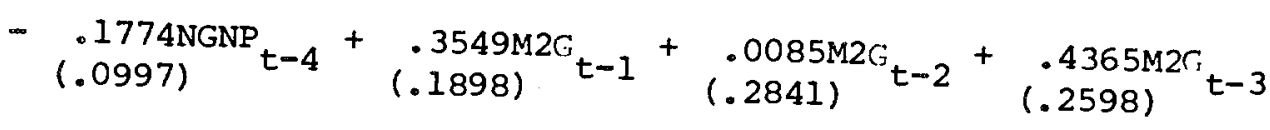

$$
\begin{aligned}
& -.0799 M 2 G_{t-4}+u_{t} \\
& \mathrm{R}^{2}=.3712 \quad \text { Standard Frror }=.00880 \quad \text { Durbin-Watson }=2.11
\end{aligned}
$$


(8)

$$
\begin{aligned}
& \pi_{t}=\frac{-.0008}{(.0011)}+\underset{(.1054)}{.2477 \pi}{ }^{t-1}+\underset{(.1087)}{.1598 \pi} t-2+\underset{(.1089)}{.2744 \pi} t-3+\frac{.0466 \pi}{(.1036)} t-4
\end{aligned}
$$

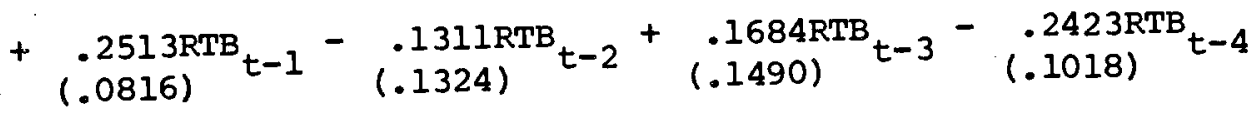

$$
\begin{aligned}
& +\underset{(.0935)}{.1234 \mathrm{M} 2 \mathrm{G}_{\mathrm{t}-1}}+\underset{(.1104)}{.0011 \mathrm{M} 2 \mathrm{G}_{\mathrm{t}-2}}+\underset{(.1090)}{.1874 \mathrm{M} 2 \mathrm{G}_{\mathrm{t}-3}}+\underset{(.0868)}{.2240 \mathrm{M} 2 \mathrm{G}_{\mathrm{t}-4}} \\
& \mathrm{R}^{2}=.7411 \text { Standard Error }=.00347 \quad \text { Durbin-Watson }=1.74
\end{aligned}
$$

where

$$
\begin{aligned}
\text { NGNP } & =\text { quarterly rate of growth of nominal GNP } \\
\pi & =\text { quarterly rate of growth of the GNP deflator } \\
M 2 G & =\text { quarterly rate of growth of average M2 } \\
\text { RTB } & =\text { average treasury bill rate }
\end{aligned}
$$

and standard errors of the coefficients are in parentheses. ${ }^{13}$ Table 1 provides F-statistics of the joint tests for significant explanatory power of the four lagged values of each variable in the list of potential explanatory variables. 14 Nominal GNP Growth as the Aggregate Demand, $x$ Variable

The models in Table 2 follow Robert Gordon and Jean Grossman in using nominal GNP growth as the aggregate demand variable in the output and unemployment equations. They have been estimated from the (2) and (4) systems, imposing the cross-equation constraints that the $\gamma$ are equal in both equations. The resulting $\gamma$ estimates for the models of Table 2 and the tables that follow can be found in Appendix III. Twenty lagged quarters of unanticipated nominal GNP growth have been included in the models because coefficients on lags as far back as this are significantly different from zero at the $5 \% 1$ evel--a result confirmed by Gordon.

The signs and shape of the 2.1 and 2.2 models are sensible, with an increase in unanticipated nominal GNP growth usually associated with an increase in output or a decrease in unemployment. The fit of these equations 
TABLE 1

Joint Tests for Significant Explanatory Power in (7) and (8) of Four Lags of Each Variable.

\begin{tabular}{|c|c|c|c|c|}
\hline \multirow[t]{2}{*}{ Variable } & \multicolumn{2}{|c|}{ NGNP Forecasting Equation (7) } & \multicolumn{2}{|c|}{$\pi$ Forecasting Equation ( 8 ) } \\
\hline & $\begin{array}{l}\text { F- } \\
\text { Statistic }\end{array}$ & $\begin{array}{c}\text { Marginal } \\
\text { Significance } \\
\text { Level }\end{array}$ & $\begin{array}{c}\text { F- } \\
\text { Statistic }\end{array}$ & $\begin{array}{c}\text { Marginal } \\
\text { Significance } \\
\text { Level }\end{array}$ \\
\hline NGNP & 2.24 & .0716 & 1.44 & .2292 \\
\hline $\begin{array}{l}\pi \\
\text { RTB } \\
\text { M2G } \\
\text { M1G } \\
\text { UN } \\
\text { RGNP } \\
\text { G } \\
\text { BOP } \\
\text { GDEBT } \\
\text { SURPLUS }\end{array}$ & $\begin{array}{c}.96 \\
.11 \\
5.65 * * \\
.48 \\
1.62 \\
.94 \\
2.47 \\
.61 \\
.92 \\
1.66\end{array}$ & $\begin{array}{l}.4342 \\
.9787 \\
.0005 \\
.7503 \\
.1774 \\
.4453 \\
.0513 \\
.6566 \\
.4566 \\
.1676\end{array}$ & $\begin{array}{c}8.38 * * \\
5.01 * * \\
3.04^{*} \\
.60 \\
.76 \\
1.44 \\
1.55 \\
2.26 \\
.61 \\
1.35\end{array}$ & $\begin{array}{l}1.1 \times 10^{-5} \\
.0012 \\
.0219 \\
.6638 \\
.5546 \\
.2292 \\
.1965 \\
.0705 \\
.6567 \\
.2595\end{array}$ \\
\hline
\end{tabular}

The F-statisticstest the null hypothesis that the coefficients on the four lagged values of each of these variables equals zero. The marginal significance level is the probability of finding that value of $F$ or higher under the null hypothesis. For the NGNP and M2G tests in (7), the F-statistic is F-statistic is $F(4,83)$, while for the tests of the other variables in (7), the the F-statistic istributed as $F(4,79)$. For the $\pi, R T B$ and $M 2 G$ tests in ( 8 ) variables in $(8)$, distributed as $F(4,79)$, while for the tests of the other

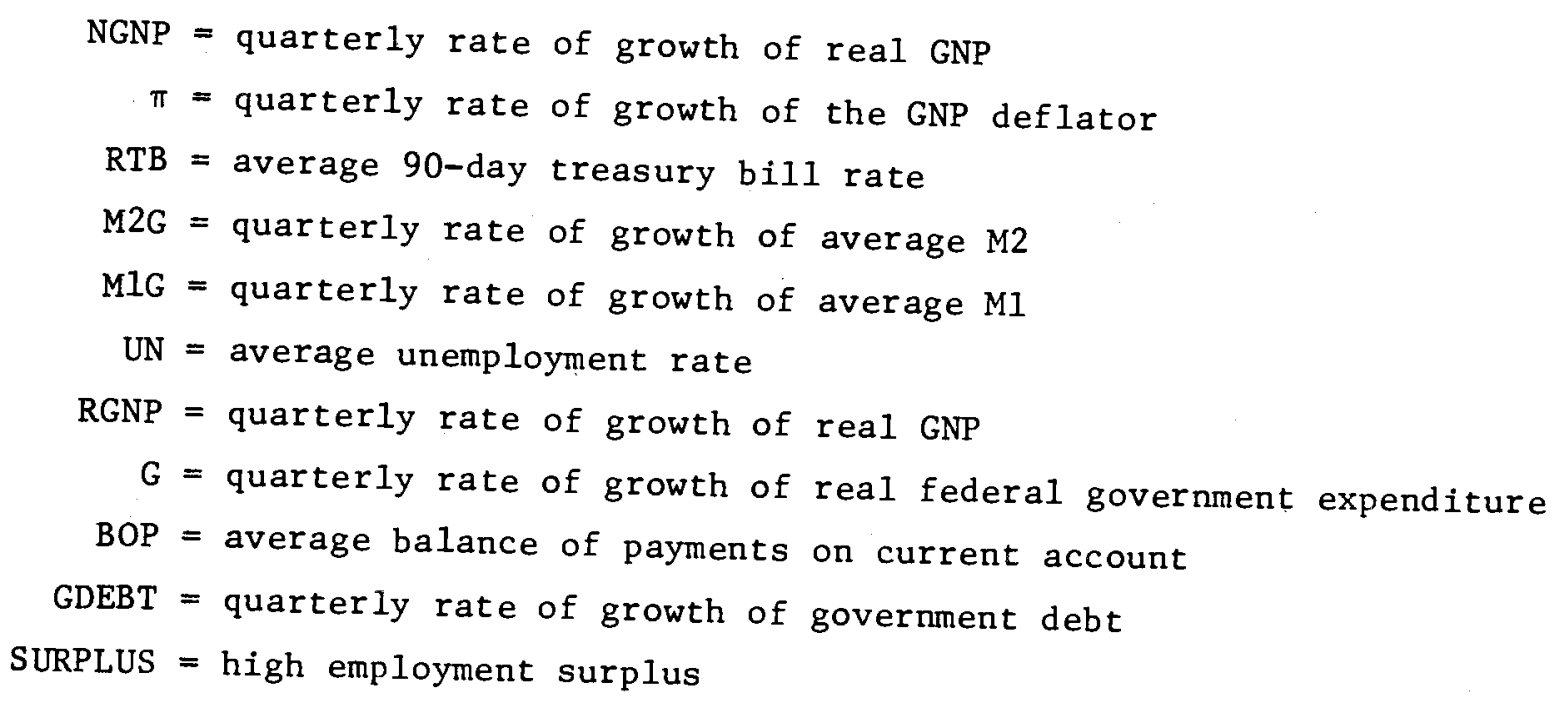




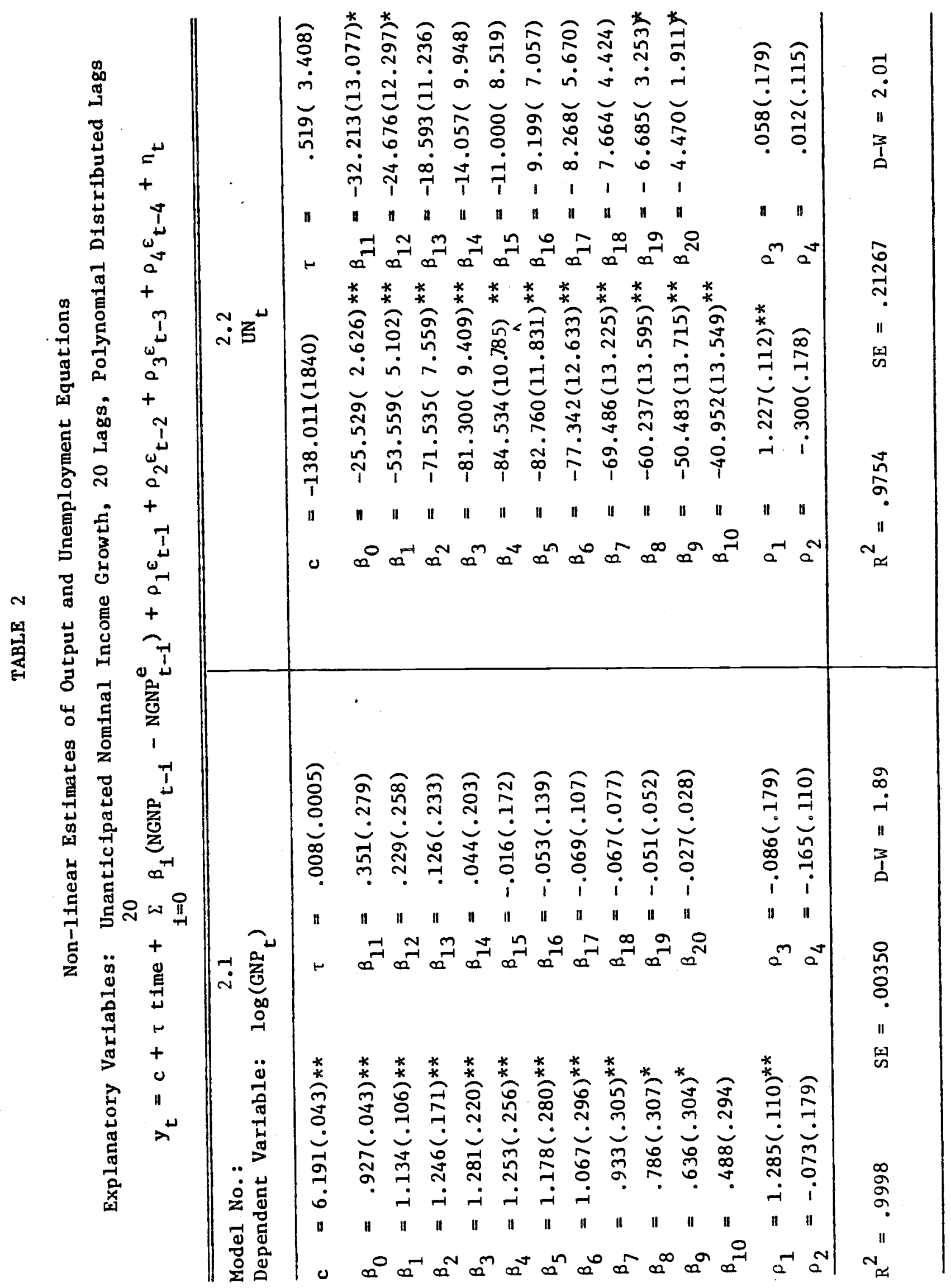


$10 \mathrm{c}$

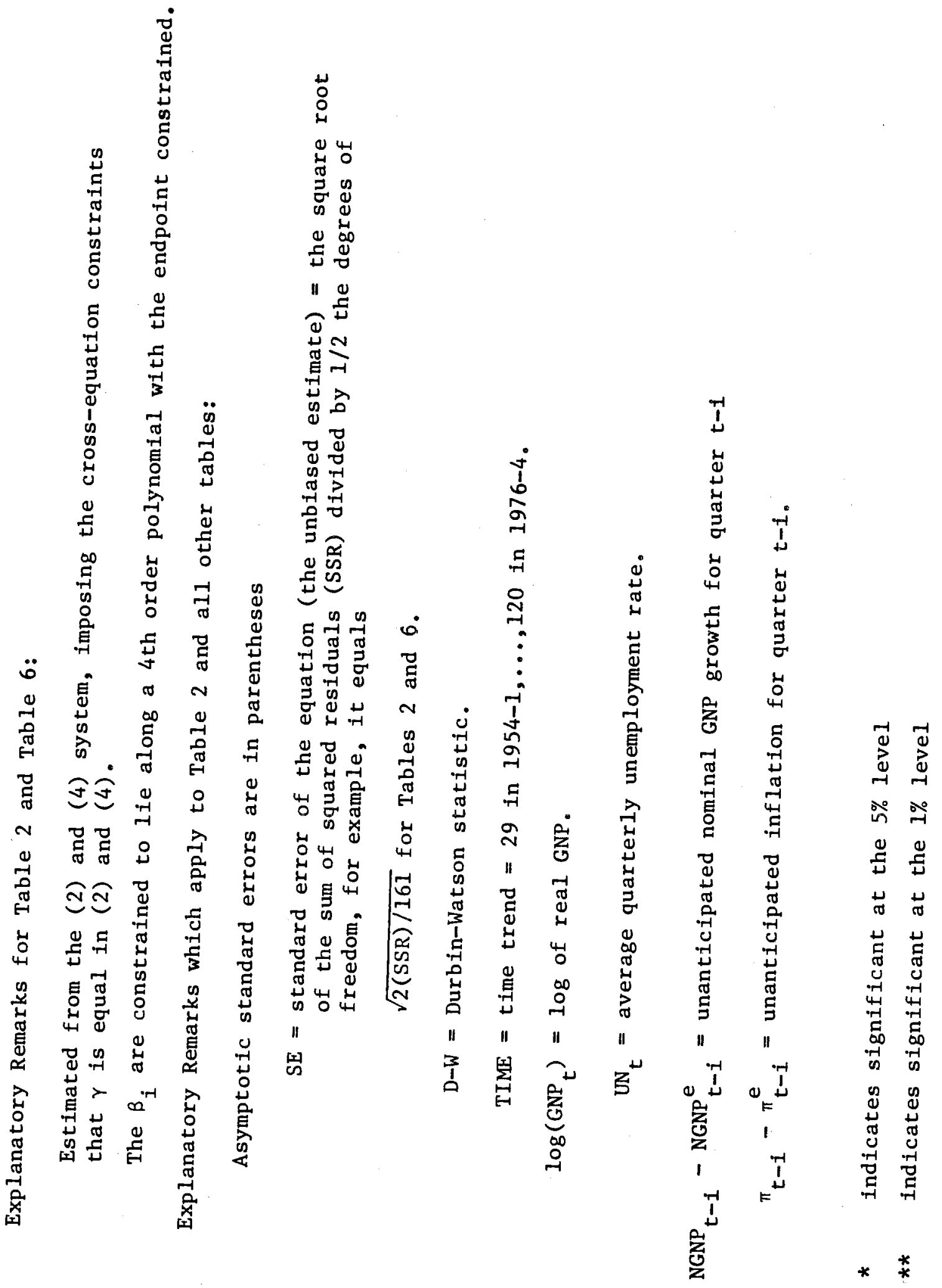


is also good--for example, compare them with the results in my earlier paper, or those in the Table 6--and several of the coefficients on unanticipated nominal GNP growth even exceed their asymptotic standard errors by a factor of ten. The good fit is not surprising because we would expect nominal GNP fluctuations to accurately track short-run movements in real GNP or unemployment if price level movements are smooth.

Despite these attractive results, Table 3 indicates that the MRE hypothesis is not supported. Both the unemployment and output models lead to strong rejections of the joint hypothesis: In the output model, the rejection is at the .00001 level, and is at the .0009 level in the unemployment model. 15 The most interesting aspect of these results is that there is very little contribution to these rejections from the rationality constraints. In both models, the data do not reject the rationality of expectations. The culprit behind the joint hypothesis rejections is the neutrality proposition. These neutrality rejections are exceedingly strong: the probability of finding that value of the likelihood ratio statistic or higher under the nul1 hypothesis of neutrality is 1 in 2000 for the unemployment model, and 1 in 200,000 for the output model! Clearly in these models, anticipated nominal GNP growth does matter, and rejection of the neutrality constraints cannot be blamed on the failure of the maintained hypothesis of rationality. 16 We can achieve a deeper understanding of the test results in Table 3 by studying the estimated output and unemployment equations where current and lagged anticipated nominal growth are added as explanatory variables. Tables 4 and 5 contain the results from the (2) and (6) system with rational expectations imposed. As we would expect from Table 3, many of the coefficients on anticipated nominal GNP growth are significantly different from zero at the 18 level, with some asymptotic t-statistics even exceeding seven in absolute value. Of course these coefficients could be statistically significant, yet unimportant from an economic viewpoint. This is clearly not the case. The 
TABLE 3

Likelihood Ratio Tests for the Models of TABLE 2

\begin{tabular}{llc}
\hline Model No. & 2.1 & 2.2 \\
\hline
\end{tabular}

Joint Hypothesis

Likelihood Ratio Statistic

$$
\begin{array}{lcc}
\text { Likelihood Ratio Statistic } & x^{2}(11)=43.19 * * & \chi^{2}(11)=31.69 * * \\
\text { Marginal Significance Level } & 1.01 \times 10^{-5} & .0009
\end{array}
$$

Neutrality

Likelihood Ratio Statistic

$x^{2}(4)=30.22^{* *}$

$x^{2}(4)=19 \cdot 90 * *$

Marginal Significance Level

$$
4.41 \times 10^{-6}
$$
.0005

\section{Rationality}

Likelihood Ratio Statistic

Marginal Significance Level

$\begin{array}{cc}x^{2}(7)=12.86 & x^{2}(7)=11.28 \\ .0756 & .1269\end{array}$




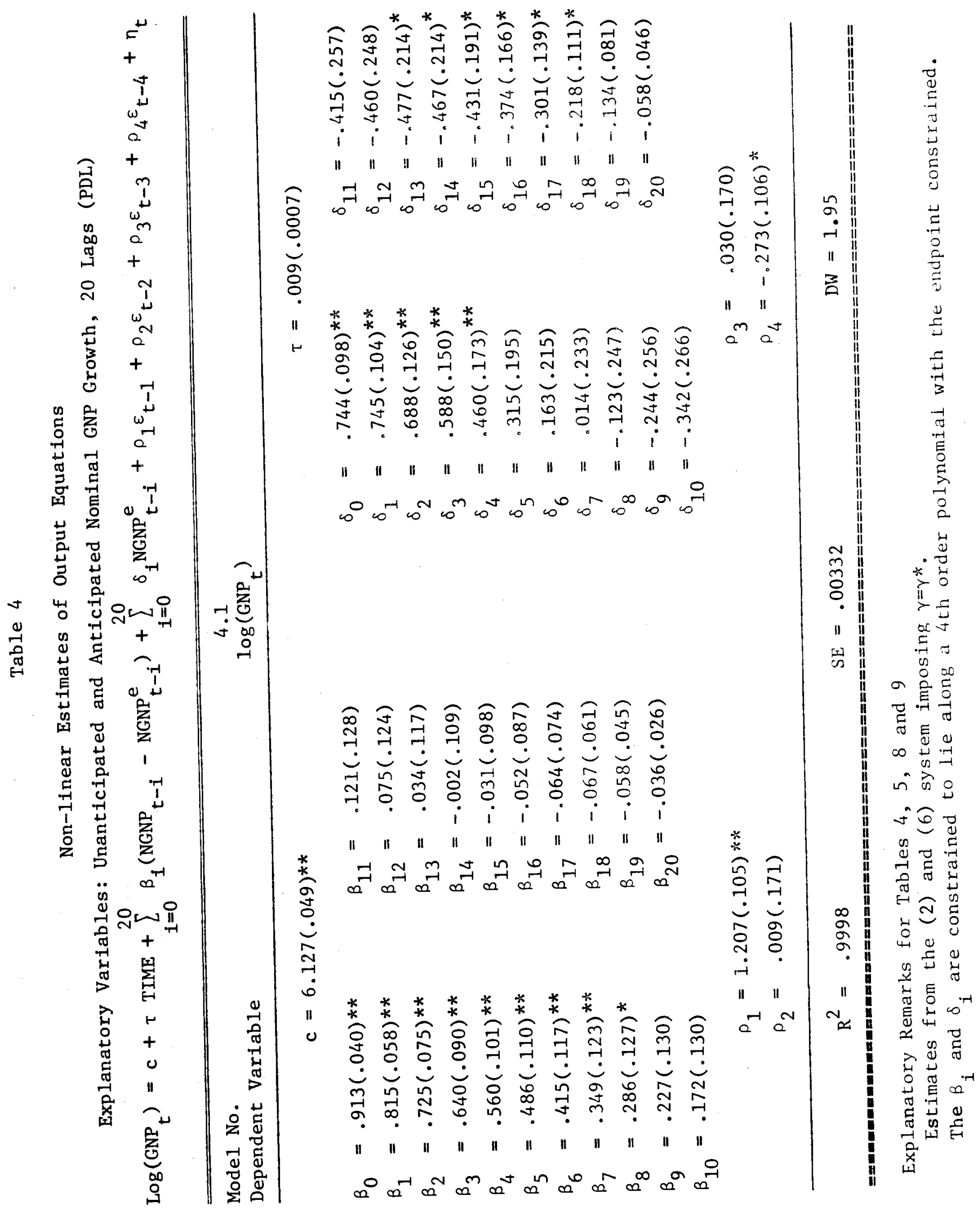



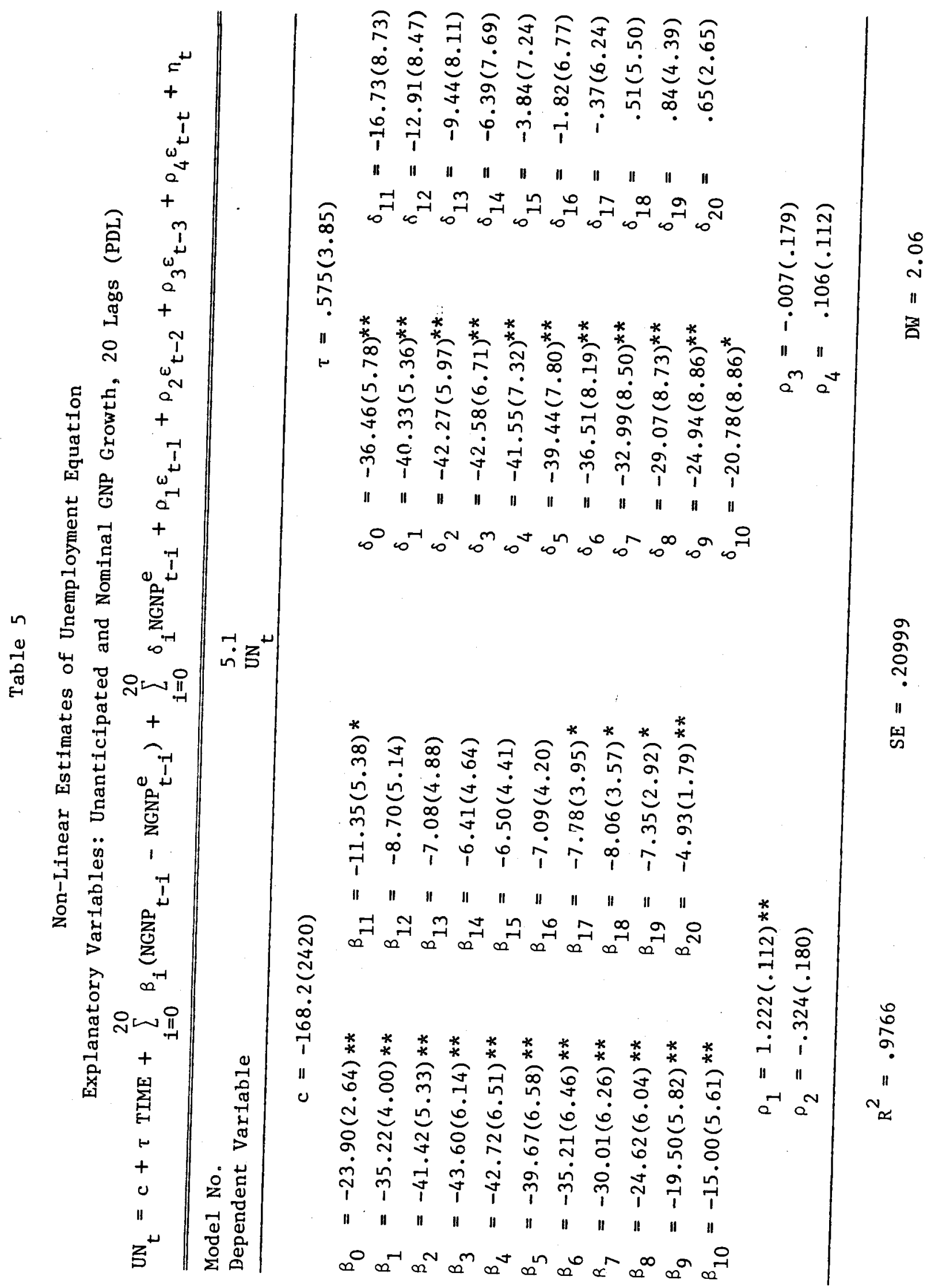
coefficients on anticipated nominal GNP growth are of a similar magnitude to the coefficients on unanticipated nominal GNP growth. Contrary to what is implied by the MRE hypothesis, anticipated aggregate demand policy as represented by nominal GNP growth does not appear to be obviously less important than unanticipated aggregate demand policy.

Inflation as the Aggregate Demand, $x_{t}$, Variable

The next set of results explores a Lucas (1973) supply function of the type estimated by Sargent $(1976 a) .^{17}$ Table 6 presents the output and unemployment equations estimated from the constrained (2) and (4) system. The seventeen quarter lag length on unanticipated inflation has been included in the models again because coefficients on lags as far back as this are significantly different from zero at the 5 ; level.

Table 6 confirms Ray Fair's finding for a similar sample period that the coefficients on unanticipated inflation have the opposite sign to that predicted by the Lucas supply function. Sargent's (1976a) contrádictory finding probably stems from his use of a sample period that does not include 1974-1975. Sargent takes unanticipated inflation to be a response to aggregate demand shifts which might have been a more reasonable assumption. for the sample period he used in estimation. However, it is plausible that the supply shock effect of a decreased supply of food and energy during 1974 and 75--which would be linked to an unanticipated upward movement in the U.S. Inflation rate coupled with an output decline--is dominating the aggregate demand effects on unanticipated inflation in the data used here. Thus the estimated coefficients on unanticipated inflation are not inherently contradictory to the MRE hypothesis, yet they are certainly not supportive. 


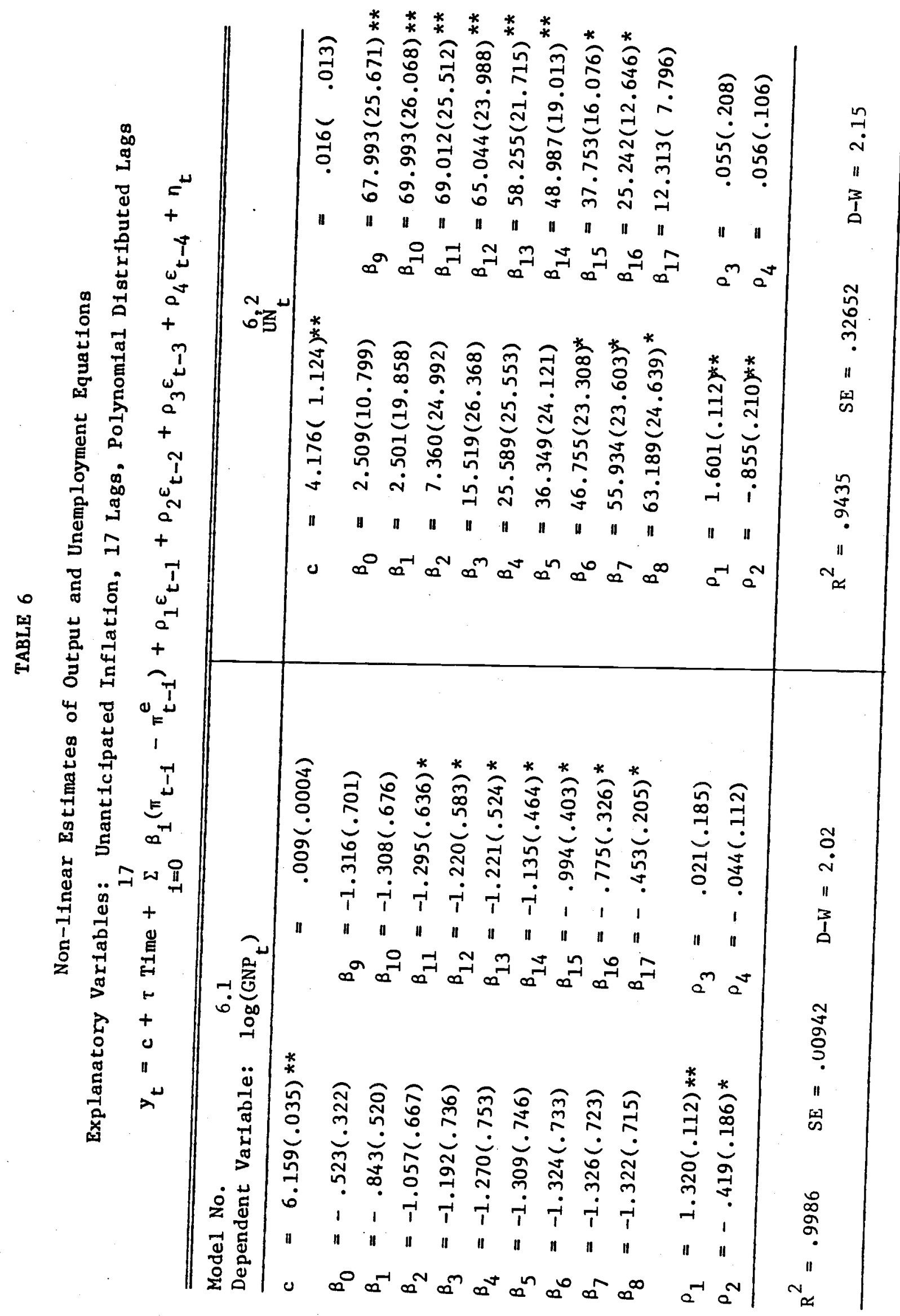




\section{TABLE 7}

Likelthood Ratio Tests for the Models of TABLE 6

\begin{tabular}{lcc}
\hline \multicolumn{1}{c}{ Model No. } & 6.1 & 6.2 \\
\hline Joint Hypothesis & $x^{2}(15)=28.45 *$ & $x^{2}(15)=32.34 * *$ \\
Likelihood Ratio Statistic & .0189 & .0058 \\
Marginal Significance Level & $x^{2}(4)=18.52 * *$ \\
Neutrality & .0010 & $x^{2}(4)=13.20^{*}$ \\
Likelihood Ratio Statistic & & .0104 \\
Marginal Significance Level & $x^{2}(11)=10.23$ \\
Rationality & .5098 & $x^{2}(11)=20.16 *$ \\
Likelihood Ratio Statistic & & .0432 \\
Marginal Significance Level &
\end{tabular}


The likelihood ratio tests in Table 7 indicate that the MRE hypothesis is not supported for the models with inflation as the aggregate demand variable. The joint hypothesis is rejected for both models at the $5 \%$ significance level, with the neutrality hypothesis the major contributor to these rejections. The neutrality constraints are rejected at the .001 marginal significance level for the output model and .01 for the unemployment model. The rationality constraints again fare better with the marginal significance levels equaling .51 for the output model and .04 for the unemployment model. The evidence then again seems to be quite negative on the neturality implication of the MRE hypothesis, but far less so on the rationality implication.

Tables 8 and 9 show that, contrary to the MRE hypothesis, the effects from unanticipated inflation are not stronger than anticipated inflation. Not only are the coefficients on anticipated inflation substantially larger than the unanticipated coefficients, but their asymptotic t-statistics are substantially larger as well.

Overall then, the Lucas supply model estimated here is not successful. It has coefficients with the "wrong" sign, fits the data worse than a corresponding model with money growth as the aggregate demand variable as in Barro and Rush and my earlier paper, and leads to strong rejections of neutrality with anticipated inflation proving to be more significantly correlated with output and unemployment than unanticipated inflation.

\section{CONCLUSION}

The empirical evidence here does not support the proposition implied by the MRE hypothesis that only unanticipated aggregate demand policy matters. This is consistent with the findings in my earlier paper. With the aggregate demand policy variable specified to be either nominal GNP growth or inflation, anticipated policy seems to matter a lot. Anticipated aggregate 


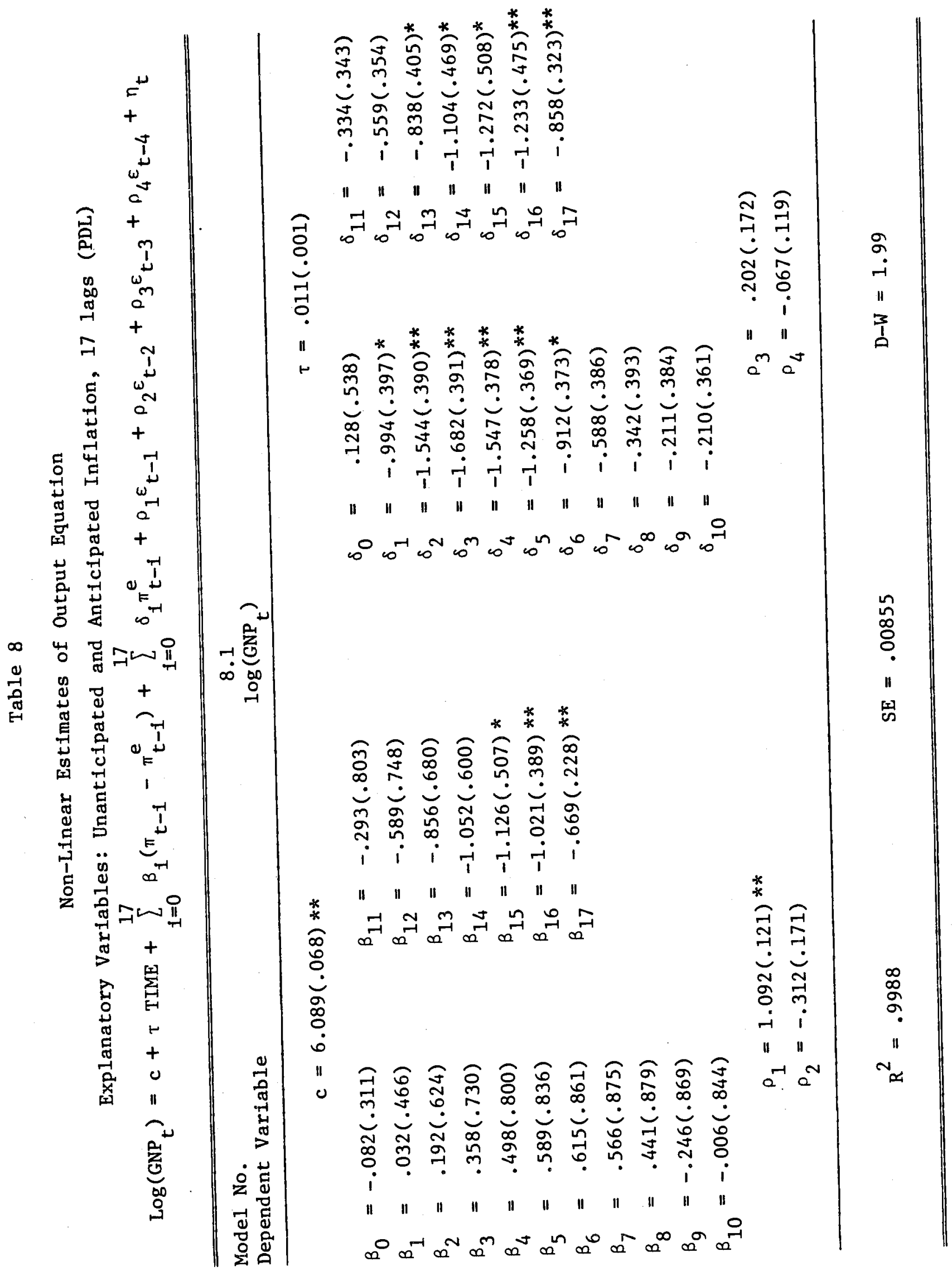




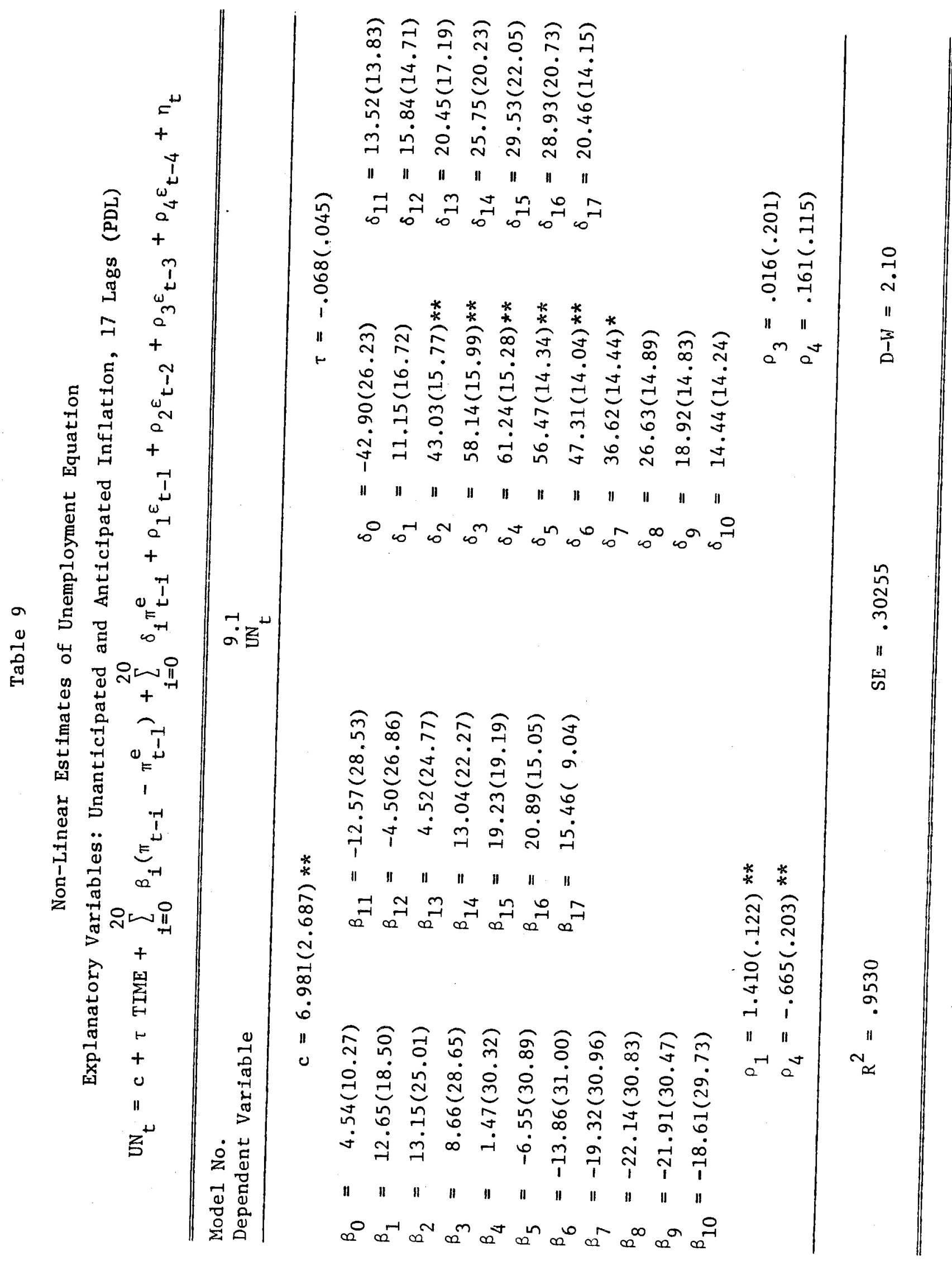


demand variables are not found to be much less important than the unanticipated variables in the estimated models, and the constraints implied by neutrality are rejected in every test in this paper. Furthermore, these rejections are frequently at exceedingly small marginal significance levels. For example, in one test the probability of finding that value of the likelihood ratio statistic under the null hypothesis of neutrality is only 1 in 200,000 . The hypothesis of rational expectations, the other element in the MRE hypothesis, fares much better in the empirical tests here. Although the rationality hypothesis does not come out unscathed--there is one rejection at the five percent level, but just barely--it is not rejected in any other tests in the text at the $5 \%$ level. 18 Rejections of the joint hypothesis of rationality and neutrality are thus seen to occur primarily because of the rejections of neutrality rather than rationality. This result might give some encouragement to those who are willing to assume rationality of expectations in constructing their macro models, yet are unwilling to assert the short-run neutrality of policy.

There is one qualification of the results that warrants further discussion. This paper has followed previous research in this area by using the identifying assumption that the output and unemployment equations are true reduced forms. However, with inflation or nominal GNP growth as the aggregate demand variable, this assumption is not without suspicion. It is not clear whether the invalidity of this assumption might lead to rejections of the MRE hypothesis even if it were true. Some caution in interpreting these results is therefore warranted. However, this work along with my earlier paper does cast doubt on previous evidence that is cited as supporting the view that only unanticipated macro policy is relevant to the business cycle. 


\section{APPENDIX I}

VARIABLES AND SOURCES OF DATA

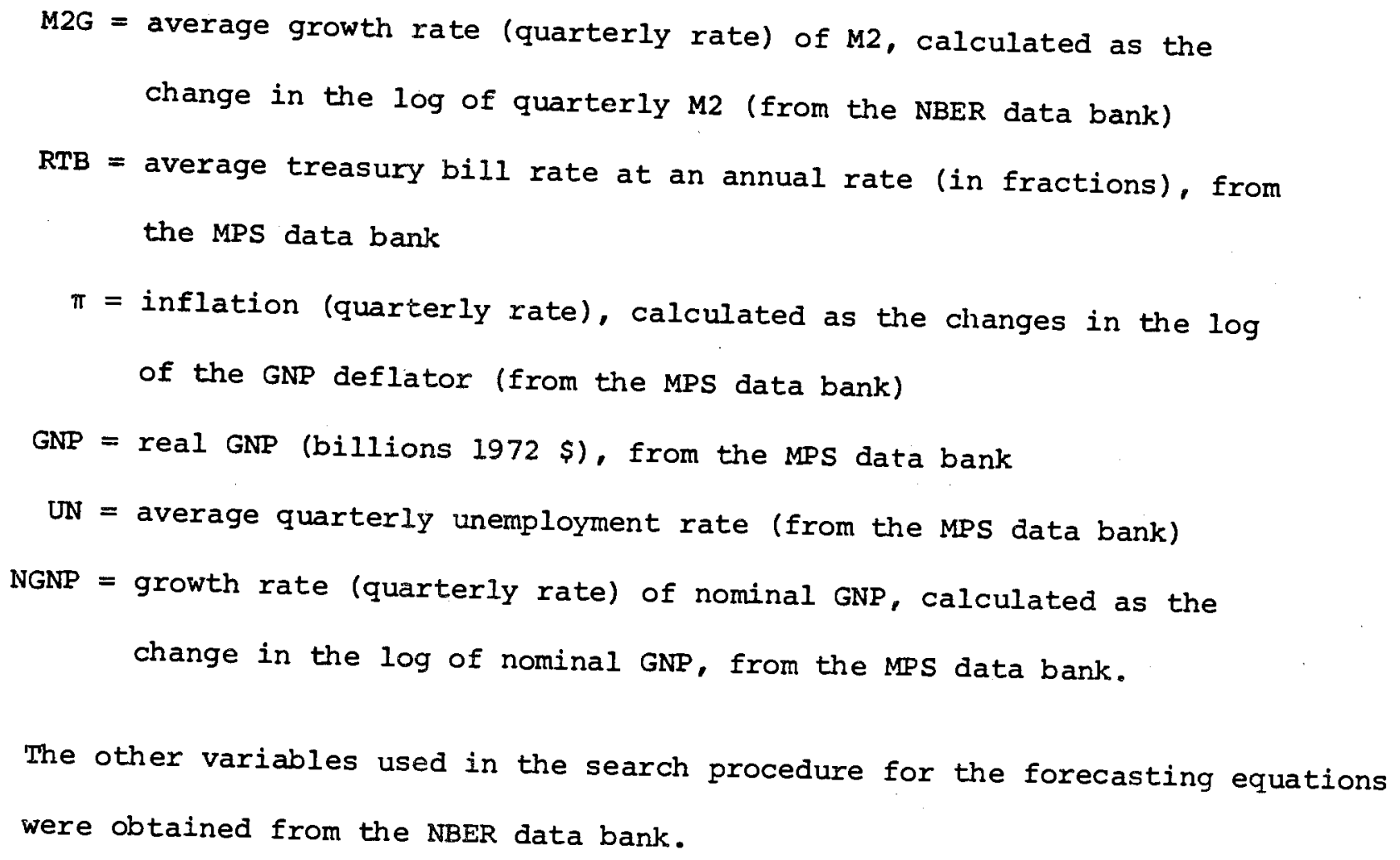


Freely Estimated Output and Unemployment Models

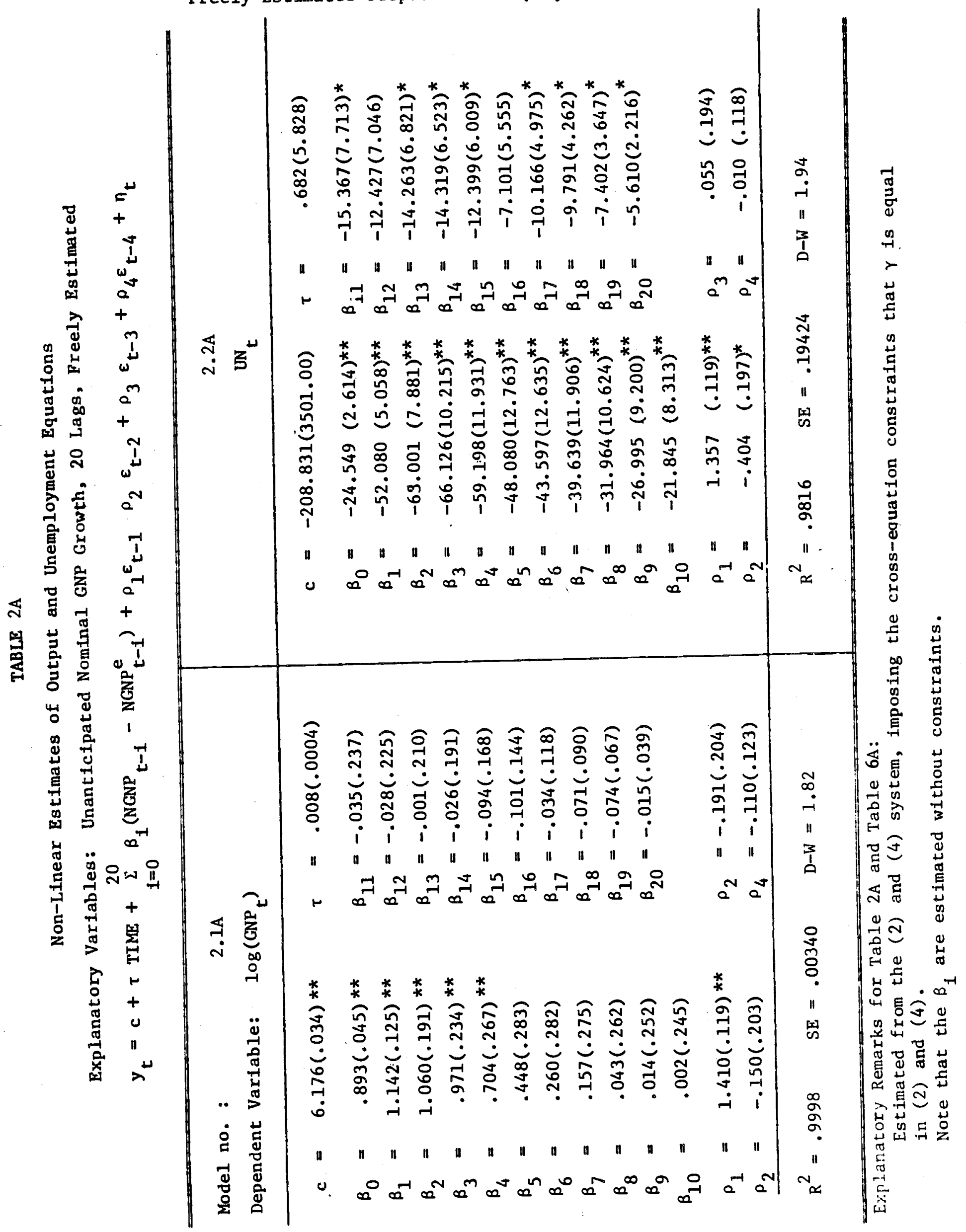


TABLE $3 A$

Likelihood Ratio Tests for the Models of Table 2A

\begin{tabular}{lcc}
\hline Model No. & $2.1 \mathrm{~A}$ & $2.2 \mathrm{~A}$ \\
\hline $\begin{array}{l}\text { Joint Hypothesis } \\
\text { Likelihood Ratio Statistic } \\
\text { Marginal Significance Level }\end{array}$ & $x^{2}(28)=57.89 * *$ & $\chi^{2}(28)=71.21 * *$ \\
& .0008 & $1.25 \times 10^{-5}$ \\
$\begin{array}{l}\text { Neutrality } \\
\text { Likelihood Ratio Statistic } \\
\text { Marginal Significance Level }\end{array}$ & $x^{2}(21)=56.11^{* *}$ & $x^{2}(21)=64.04 * *$ \\
& $4.86 \times 10^{-5}$ & $3.07 \times 10^{-6}$ \\
$\begin{array}{l}\text { Rationality } \\
\text { Likelihood Ratio Statistic } \\
\text { Marginal Significance Level }\end{array}$ & $x^{2}(7)=1.85$ & $x^{2}(7)=4.20$ \\
\end{tabular}




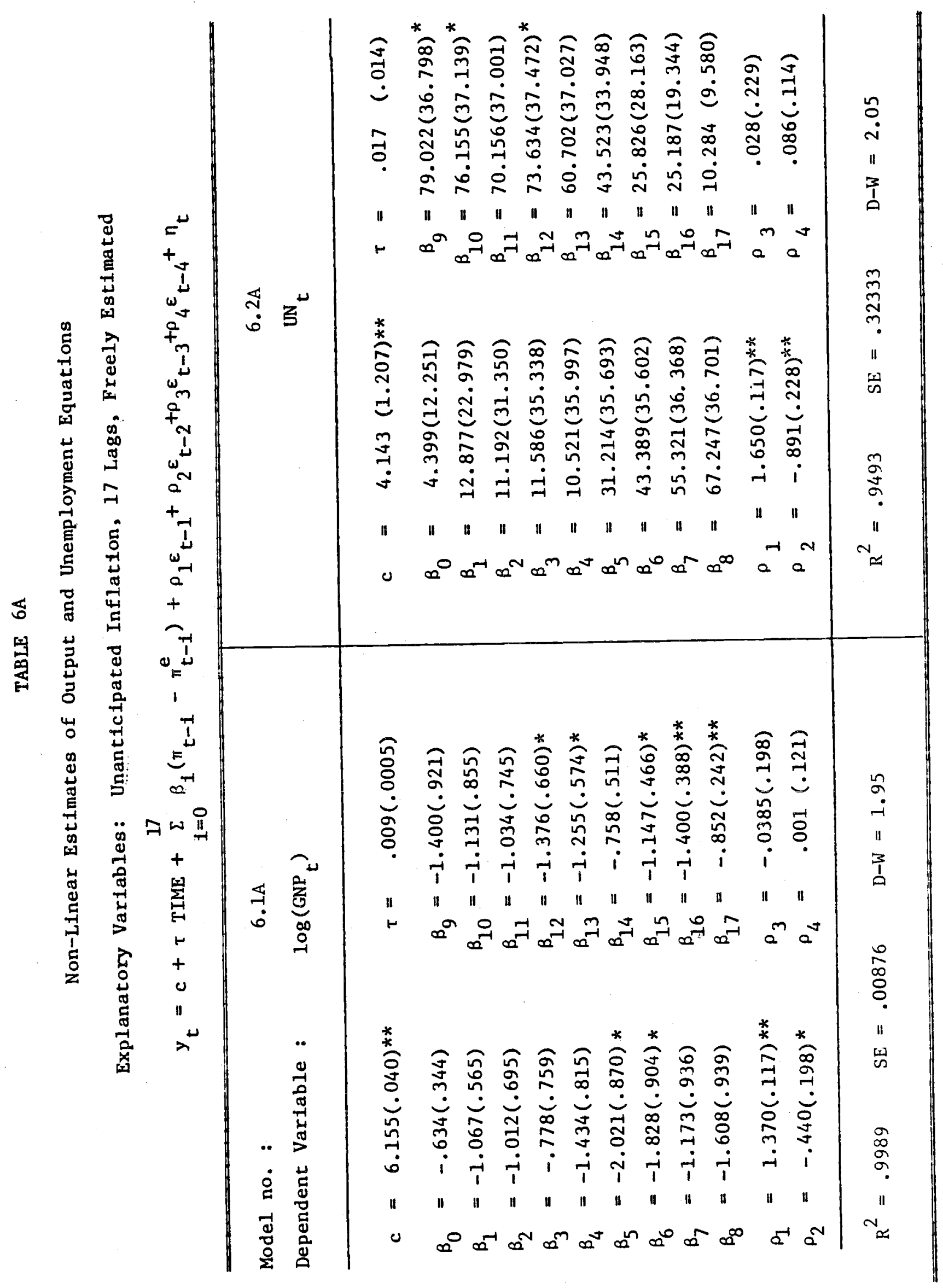


TABLE 7A

Likelihood Ratio Tests for the Models of Table 6A

\begin{tabular}{|c|c|c|}
\hline Model No. & $6.1 \mathrm{~A}$ & $6.2 \mathrm{~A}$ \\
\hline $\begin{array}{l}\text { Joint Hypothesis } \\
\text { Likelihood Ratio Statistic } \\
\text { Marginal Significance Level }\end{array}$ & $\begin{array}{c}x^{2}(29)=64.38 * * \\
.0002\end{array}$ & $\begin{array}{c}x^{2}(29)=57.03 * \star \\
.0014\end{array}$ \\
\hline $\begin{array}{l}\text { Neutrality } \\
\text { Likelihood Ratio Statistic } \\
\text { Marginal Significance Level }\end{array}$ & $\begin{array}{c}x^{2}(18)=43.51 * * \\
.0007\end{array}$ & $\begin{array}{l}x^{2}(18)=33.93 * \\
.0129\end{array}$ \\
\hline $\begin{array}{l}\text { Rationality } \\
\text { Likelihood Ratio Statistic } \\
\text { Marginal Significance Level }\end{array}$ & $\begin{array}{l}x^{2}(11)=22.33^{*} \\
.0219\end{array}$ & $\begin{array}{l}x^{2}(11)=32.01^{*} \\
.0008\end{array}$ \\
\hline
\end{tabular}




\section{APPENDIX III}

Jointly Estimated Forecasting Equations

TABLE A1 Nomina1 GNP Growth Forecasting Equations, Estimated Jointly
with Output and Unemployment Equations

For Mode1 非

\begin{tabular}{|c|c|c|c|c|c|c|c|}
\hline Coefficient of & 2.1 & 2.2 & 4.1 & 5.1 & $2.1 \mathrm{~A}$ & $2.2 \mathrm{~A}$ & OLS \\
\hline Constant Term & $\begin{array}{l}.0084 * * \\
(.0022)\end{array}$ & $\begin{array}{l}.0079 * * \\
(.0017)\end{array}$ & $\begin{array}{l}.0068 * * \\
(.0024)\end{array}$ & $\begin{array}{l}.0076 * * \\
(.0025)\end{array}$ & $\begin{array}{l}.0113 * * \\
(.0025)\end{array}$ & $\begin{array}{l}.0116 * * \\
(.0024)\end{array}$ & $\begin{array}{l}.0068^{* *} \\
(.0025)\end{array}$ \\
\hline $\mathrm{NGNP}_{t-1}$ & $\begin{array}{l}.3139 * * \\
(.0952)\end{array}$ & $\begin{array}{l}.4437 * * \\
(.1007)\end{array}$ & $\begin{array}{c}.1481 \\
(.0956)\end{array}$ & $\begin{array}{l}.2645 * * \\
(.0934)\end{array}$ & $\begin{array}{l}.3293^{* *} \\
(.1112)\end{array}$ & $\begin{array}{l}.3000 * * \\
(.1120)\end{array}$ & $\begin{array}{l}.2209^{*} \\
(.1047)\end{array}$ \\
\hline$N_{t-2}$ & $\begin{array}{l}.0587 \\
(.0485)\end{array}$ & $\begin{array}{c}-.0062 \\
(.0959)\end{array}$ & $\begin{array}{l}-.1712 \\
(.0943)\end{array}$ & $\begin{array}{l}-.1470 \\
(.0908)\end{array}$ & $\begin{array}{l}-.1141 \\
(.1104)\end{array}$ & $\begin{array}{c}-.1390 \\
(.1135)\end{array}$ & $\begin{array}{c}-.1368 \\
(.1086)\end{array}$ \\
\hline$N_{t-3}$ & $\begin{array}{l}.0643 \\
(.0456)\end{array}$ & $\begin{array}{l}.1448 \\
(.0894)\end{array}$ & $\begin{array}{l}-.0131 \\
(.0911)\end{array}$ & $\begin{array}{l}.1082 \\
(.0902)\end{array}$ & $\begin{array}{l}.0995 \\
(.1081)\end{array}$ & $\begin{array}{l}.1540 \\
(.1112)\end{array}$ & $\begin{array}{l}.0407 \\
(.1071)\end{array}$ \\
\hline $\mathrm{NGNP}_{t-4}$ & $\begin{array}{l}.0177 \\
(.0444)\end{array}$ & $\begin{array}{l}-.0900 \\
(.0752)\end{array}$ & $\begin{array}{l}-.1054 \\
(.0843)\end{array}$ & $\begin{array}{l}-.2256^{* *} \\
(.0864)\end{array}$ & $\begin{array}{c}-.1898 * \\
(.0958)\end{array}$ & $\begin{array}{c}-.2061 * \\
(.0993)\end{array}$ & $\begin{array}{c}-.1774 \\
(.0997)\end{array}$ \\
\hline$M 2 G_{t-1}$ & $\begin{array}{l}-.0040 \\
(.0808)\end{array}$ & $\begin{array}{l}.2049 \\
(.1294)\end{array}$ & $\begin{array}{l}.2222 \\
(.1667)\end{array}$ & $\begin{array}{l}.1618 \\
(.1603)\end{array}$ & $\begin{array}{c}.0833 \\
(.0790)\end{array}$ & $\begin{array}{l}.1891 \\
(.1211)\end{array}$ & $\begin{array}{l}.3549 \\
(.1898)\end{array}$ \\
\hline $\mathrm{M} 2 \mathrm{G}_{\mathrm{t}-2}$ & $\begin{array}{l}-.0051 \\
(.1040)\end{array}$ & $\begin{array}{l}-.3015 \\
(.2196)\end{array}$ & $\begin{array}{l}.0074 \\
(.2245)\end{array}$ & $\begin{array}{l}.2755 \\
(.2115)\end{array}$ & $\begin{array}{l}.0307 \\
(.1038)\end{array}$ & $\begin{array}{c}-.1168 \\
(.1886)\end{array}$ & $\begin{array}{l}.0085 \\
(.2841)\end{array}$ \\
\hline$M 2 G_{t-3}$ & $\begin{array}{l}.2141 * \\
(.1037)\end{array}$ & $\begin{array}{l}.4024 \\
(.2210)\end{array}$ & $\begin{array}{l}.5786^{*} \\
(.2312)\end{array}$ & $\begin{array}{l}.1877 \\
(.2092)\end{array}$ & $\begin{array}{l}.1828 \\
(.1035)\end{array}$ & $\begin{array}{c}.2397 \\
(.1874)\end{array}$ & $\begin{array}{l}.4365 \\
(.2598)\end{array}$ \\
\hline$M 2 G_{t-4}$ & $\begin{array}{c}-.1332 \\
(.0895)\end{array}$ & $\begin{array}{l}-.2474 \\
(.1422)\end{array}$ & $\begin{array}{l}.0180 \\
(.1806)\end{array}$ & $\begin{array}{l}-.0120 \\
(.1775)\end{array}$ & $\begin{array}{l}-.0631 \\
(.0885)\end{array}$ & $\begin{array}{l}-.0778 \\
(.1362)\end{array}$ & $\begin{array}{l}-.0799 \\
(.2103)\end{array}$ \\
\hline $\mathrm{R}^{2}$ & .2017 & .2341 & .3453 & .3552 & .2943 & .2874 & .3712 \\
\hline SE & .00994 & .00974 & .00912 & .00905 & .00987 & .00992 & .00880 \\
\hline$D-W$ & 1.86 & 2.14 & 1.93 & 2.22 & 2.10 & 2.04 & 2.11 \\
\hline
\end{tabular}

Explanatory Remarks for Tables A1 and A2: Forecasting equations were estimated with the output or unemployment equation imposing the cross-equation constraints that $\gamma$ is equal in both equations. For purposes of comparison, ols column shows the estimate of the unconstrained forecasting equation in (7) or (8). 
TABLE A2

Inflation Forecasting Equations, Estimated Jointly with Output and Unemployment Equations

For Model \#

\begin{tabular}{|c|c|c|c|c|c|c|c|}
\hline Coefficient of & 6.1 & 6.2 & 8.1 & 9.1 & $6.1 \mathrm{~A}$ & $6.2 \mathrm{~A}$ & OLS \\
\hline Constant Term & $\begin{array}{l}-.0011 \\
(.0010)\end{array}$ & $\begin{array}{l}-.0012 \\
(.0010)\end{array}$ & $\begin{array}{l}-.0005 \\
(.0011)\end{array}$ & $\begin{array}{l}-.0005 \\
(.0011)\end{array}$ & $\begin{array}{l}-.0011 \\
(.0011)\end{array}$ & $\begin{array}{l}-.0012 \\
(.0011)\end{array}$ & $\begin{array}{l}-.0008 \\
(.0011)\end{array}$ \\
\hline$\pi_{t-1}$ & $\begin{array}{l}.2040 * \\
(.1030)\end{array}$ & $\begin{array}{l}.2405 * \\
(.1039)\end{array}$ & $\begin{array}{l}.2408 * \\
(.0953)\end{array}$ & $\begin{array}{l}.2225 * * \\
(.0861)\end{array}$ & $\begin{array}{l}.2126 * \\
(.1028)\end{array}$ & $\begin{array}{l}.2343 * \\
(.1088)\end{array}$ & $\begin{array}{l}.2477 * \\
(.1054)\end{array}$ \\
\hline$\pi_{t-2}$ & $\begin{array}{l}.1259 \\
(.1053)\end{array}$ & $\begin{array}{l}.1314 \\
(.1067)\end{array}$ & $\begin{array}{l}.1491 \\
(.0993)\end{array}$ & $\begin{array}{l}.1710 \\
(.0804)\end{array}$ & $\begin{array}{l}.0976 \\
(.1056)\end{array}$ & $\begin{array}{l}.1580 \\
(.1100)\end{array}$ & $\begin{array}{l}.1598 \\
(.1087)\end{array}$ \\
\hline$\pi_{t-3}$ & $\begin{array}{l}.2280 * \\
(.1048)\end{array}$ & $\begin{array}{l}.2087 * \\
(.1057)\end{array}$ & $\begin{array}{l}.2249 * \\
(.0999)\end{array}$ & $\begin{array}{l}.2196^{*} \\
(.0815)\end{array}$ & $\begin{array}{l}.1810 \\
(.1034)\end{array}$ & $\begin{array}{l}.2271 * \\
(.1088)\end{array}$ & $\begin{array}{l}.2744 * \\
(.1089)\end{array}$ \\
\hline$\pi_{t-4}$ & $\begin{array}{l}.0888 \\
(.1003)\end{array}$ & $\begin{array}{l}.0240 \\
(.1020)\end{array}$ & $\begin{array}{l}.0549 \\
(.0953)\end{array}$ & $(.0913)$ & $\begin{array}{l}.1541 \\
(.0957)\end{array}$ & $\begin{array}{l}-.0019 \\
(.1039)\end{array}$ & $\begin{array}{l}.0466 \\
(.1036)\end{array}$ \\
\hline $\mathrm{RTB}_{t-1}$ & $\begin{array}{l}.2284 * * \\
(.0802)\end{array}$ & $\begin{array}{l}.2280 * * \\
(.0804)\end{array}$ & $\begin{array}{l}.2890 * * \\
(.0747)\end{array}$ & $\begin{array}{l}.2269 * * \\
(.0656)\end{array}$ & $\begin{array}{l}.2400 * * \\
(.0701)\end{array}$ & $\begin{array}{l}.2432 * \star \\
(.0804)\end{array}$ & $\begin{array}{l}.2513 * \star \\
(.0816)\end{array}$ \\
\hline $\mathrm{RTB}_{t-2}$ & $\begin{array}{l}-.1093 \\
(.1308)\end{array}$ & $\begin{array}{l}-.1208 \\
(.1323)\end{array}$ & $\begin{array}{l}-.1563 \\
(.1273)\end{array}$ & $\begin{array}{l}-.1018 \\
(.0987)\end{array}$ & $\begin{array}{l}-.0490 \\
(.1092)\end{array}$ & $\begin{array}{l}-.1378 \\
(.1303)\end{array}$ & $\begin{array}{l}-.1311 \\
(.1324)\end{array}$ \\
\hline $\mathrm{RTB}_{t-3}$ & $\begin{array}{l}.1819 \\
(.1471)\end{array}$ & $\begin{array}{l}.1832 \\
(.1488)\end{array}$ & $\begin{array}{l}.1824 \\
(.1385)\end{array}$ & $\begin{array}{l}.1849 \\
(.1154)\end{array}$ & $\begin{array}{l}.0250 \\
(.1242)\end{array}$ & .1806 & $\begin{array}{l}.1684 \\
(.1490)\end{array}$ \\
\hline $\mathrm{RTB}_{t-4}$ & $\begin{array}{l}-.2408 * \\
(.0991)\end{array}$ & $\begin{array}{l}-.2134 * \\
(.0991)\end{array}$ & $\begin{array}{l}-.2366 * \\
(.0936)\end{array}$ & $\begin{array}{l}-.2530 * * \\
(.0845)\end{array}$ & $\begin{array}{l}-.1549 \\
(.0894)\end{array}$ & $\begin{array}{l}-.2107 * \\
(.0996)\end{array}$ & $\begin{array}{l}-.2423 * \\
(.1018)\end{array}$ \\
\hline$M 2 G_{t-1}$ & $(.1271)$ & $(.1147)$ & $\begin{array}{l}.0889 \\
(.0819)\end{array}$ & $\begin{array}{l}.0238 \\
(.0734)\end{array}$ & $\begin{array}{l}.1432 \\
(.0842)\end{array}$ & $\begin{array}{l}.1249 \\
(.0906)\end{array}$ & $\begin{array}{l}.1234 \\
(.0935)\end{array}$ \\
\hline$M 2 G_{t-2}$ & $\begin{array}{l}.0083 \\
(.1188)\end{array}$ & $\begin{array}{c}-.0042 \\
(.1201)\end{array}$ & $\begin{array}{c}-.0238 \\
(.1104)\end{array}$ & $\begin{array}{l}.0886 \\
(.0846)\end{array}$ & $\begin{array}{l}-.0364 \\
(.1073)\end{array}$ & $\begin{array}{c}.0052 \\
(.1167)\end{array}$ & $\begin{array}{l}.0051 \\
(.1104)\end{array}$ \\
\hline$M 2 G_{t-3}$ & $(.2093 *$ & $\begin{array}{l}.1982 \\
(.1079)\end{array}$ & $\begin{array}{l}.2082 * \\
(.1025)\end{array}$ & $\begin{array}{l}.0948 \\
(.0797)\end{array}$ & $(.2029 *$ & $\begin{array}{l}.1678 \\
(.1060)\end{array}$ & $\begin{array}{l}.1874 \\
(.1090)\end{array}$ \\
\hline$M 2 G_{t-4}$ & $\begin{array}{l}-.2212 * * \\
(.0845)\end{array}$ & $\begin{array}{l}-.1964 * \\
(.0853)\end{array}$ & $\begin{array}{l}-.2513 * * \\
(.0778)\end{array}$ & $\begin{array}{l}-.1464 * \\
(.0704)\end{array}$ & $\begin{array}{l}-.1844 * \\
(.0793)\end{array}$ & $\begin{array}{c}-.1845 * \\
(.0858)\end{array}$ & $\begin{array}{l}-.2240^{* *} \\
(.0868)\end{array}$ \\
\hline & .7369 & .7367 & .7359 & .7306 & .7263 & .7371 & .7411 \\
\hline & .00347 & .00347 & .00352 & .00355 & .00370 & .00363 & .00347 \\
\hline - & 1.92 & 1.99 & 2.01 & 1.92 & 1.65 & 1.70 & 1.74 \\
\hline
\end{tabular}




\section{FOOTNOTES}

*Associate Professor, Department of Economics, University of Chicago and Research Associate, National Bureau of Economic Research. I thank an anonymous referee; the participants in the money workshops at the University of Chicago and the University of Virginia for their helpful comments; and the National Science Foundation for research support. The usual disclaimer applies.

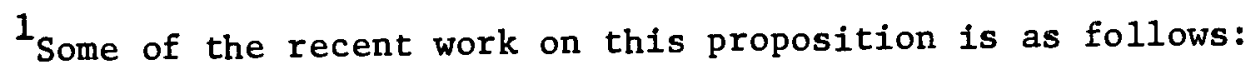
Robert Barro (1977, 1978, 1979), Robert Barro and Mark Rush, Jean Grossman, David Germany and S. Srivastava, Robert Gordon, Leonardo Leiderman, and David Small.

2 Jean Grossman and Robert Gordon.

3 Thomas Sargent (1976a) and Ray Fair.

${ }^{4}$ Note that the endogeneity of the aggregate demand variable does not necessarily produce invalid test statistics for this model. For example, in the case where only contemporaneous $M-M^{e}$ enters in equation (4), test statistics are valid even if the exogeneity of $\mathrm{X}$ is assumed when this is untrue. See Andrew Abel and the author. However, it is not clear that this desirable result--that the above assumption does not matter to the tests of interest here--carries over to the case where lagged $M-M^{e}$ enter equation (4).

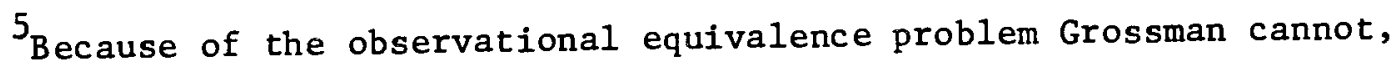
and does not, test using Barro's (1977) procedure whether the anticipated nominal GNP growth variables significantly add to the explanatory power of his equation (4) model. Instead Grossman reports results supporting the MRE hypothesis which rely on flimsy grounds for identification, namely the assumption that the lag length on nominal GNP growth cuts off at six quarters. 
${ }^{6}$ Goldfeld-Quandt tests do not reveal the presence of heteroscedasticity within the (2) and (4) equations estimated here and it is only necessary to correct for it across equations, as in my earlier paper.

7 The constrained-system is estimated with iterated non-1inear least squares and it thus approaches full information maximum likelihood (FIML). The unconstrained system is estimated using the variance-covariance matrix estimate from the constrained system in order to correct for one small sample problem. This results in a likelihood ratio statistic that is slightly more conservative: i.e., it will be less likely to reject the null hypothesis. See my earlier paper for a more detailed explanation of why this procedure was followed.

8 The PDL constraints are not rejected in models where inflation is the aggregate demand, $X$ variable. For example, in mode1 $6.1 \chi^{2}(14)=20.54$ and in model $6.2 \chi^{2}(14)=10.62$ : the critical $\chi^{2}(14)$ at $5 \%$ is 23.7 . The PDL constraints receive less support in the models using nominal GNP as the $X$ variable. They are not rejected for the 2.1 output model at the $5 \% 1$ evel, but are nearly so: $\chi^{2}(17)=26.95$, while the critical $\chi^{2}(17)$ at $5 \%$ is 27.6. However, they are rejected at the $1 \%$ level in the unemployment equation: $\chi^{2}(17)=34.91$, while the critical $\chi^{2}(17)$ at $1 \%$ is 33.4 . I did pursue experiments with an 8 th order PDL to see if this would fit the data substantially better, but it did not. Although this rejection of the PDL constraints is bothersome, the fact that the unrestricted models in Appendix II yield such similar results to those in Tables 2 and 3 indicates that imposing or not imposing the PDL constraints does not change any conclusions. ${ }^{9}$ The Durbin-Watson statistics for $\varepsilon_{t}$ range from 1.82 to 2.15 , none of which indicates the presence of first-order serial correlation. Furthermore, the Ljung and Box adjusted Q-statistics for the first twleve autocorrelations of $\varepsilon_{t}$ cannot reject the null hypothesis that these autocorrela- 
tions are zero. The $Q(12)$ statistics range from 5.84 to 15.0 , while the critical $Q(12)$ at $5 \%$ is 15.5 .

${ }^{10}$ See Thomas Sargent (1981).

${ }^{11}$ Note that a stepwise regression procedure might miss significant explanatory variables because of the order that it chooses to run the regressions. Thus some judgment must be exercised in conducting a more general search to find a specification that includes any variables with significant explanatory power.

12 Because rejections of the null hypothesis are less likely when the power of the test is reduced by the addition of irrelevant variables, a rejection at a standard significance level in a less restrictive model is even stronger evidence against the null hypothesis.

${ }^{13}$ Chow tests which split the sample in equal halves indicate that the nominal GNP growth forecasting equation does have the desirable property that the stability of the coefficients cannot be rejected. $F(9,74)=.60$ while the critical $\mathrm{F}$ at $5 \%$ is 2.0 . However, stability of the coefficients of the inflation equation is rejected: $F(13,66)=3.40$ while the critical $F$ at $5 \%$ is 1.9 .

${ }^{14}$ The $F$ tests here are not meant to describe what regressions were run in order to achieve the final specification. They only show how much marginal explanatory power each variable has, once the first specification was decided upon. The specification was approached by running regressions with many more variables than in (7) or (8) and paring the specification down by eliminating variables with little explanatory power, as well as building up the specification from regressions with fewer explanatory variables. In cases where two variables were so highly correlated that each but not both had significant explanatory power, the one that 
produced a lower standard error of the equation was chosen. An example of this is the choice of M2 over M1 growth in both equations (7) and (8). ${ }^{15}$ As in my earlier paper, the long lags for the unanticipated and anticipated nominal GNP variables are critical to the negative findings in the MRE hypothesis. For example, an output model with only seven lags of nominal GNP growth with the lag coefficients freely estimated does not reject the joint hypothesis: $x^{2}(15)=23.07$ while the critical $x^{2}(15)$ at $5 \%$ is 25.0 . As explained in my earlier paper, this failure to reject is probably due to misspecifying the lag length as too short. ${ }^{16}$ Although these rejections are consistent with the results using money growth in my earlier paper, they are substantially stronger. One possible explanation for this finding is that the higher correlation of this aggregate demand variable with output or unemployment leads to tests with greater power.

${ }^{17}$ As reported in footnote 13, the stability over time of the coefficients of the inflation forecasting equation was rejected. Thus we should be somewhat more cautious in interpreting the results here which make use of this equation. However, as discussed in my earlier paper, the specification of the forecasting equation is probably not a critical issue in the findings because the errors-in-variables problem from misspecification of the forecasting equation is probably not severe.

${ }^{18}$ I do not cite the rationality test results in Appendix II because, as the discussion in my earlier paper indicates, they may not be reliable because of small sample bias. 


\section{REFERENCES}

Abel, Andrew and Mishkin, Frederic S., "An Integrated View of Tests of Rationality, Market Efficiency and the Short-Run Neutrality of Monetary Policy," Center for Mathematical Studies in Business and Economics, Report 8113, University of Chicago, March 1981. Barro, Robert, "Unanticipated Money Growth and Unemployment in the United States," American Economic Review, March 1977, 67, no. 2, 101-115. - "Unanticipated Money, Output, and the Price Level in the United States," Journal of Political Economy, August 1978, 86, 549-580. , "Unanticipated Money Growth and Unemployment in the United States:

Reply," American Economic Review, December 1979, 69, 1004-1009. and Rush, Mark, "Unanticipated Money and and Economic Activity,"

in Stanley Fischer (ed.), Rational Expectations and Economic Policy, University of Chicago Press: Chicago 1980, 23-48. Fair, Ray C., "An Analysis of the Accuracy of Four Macroeconomic Models," Journal of Political Economy, August 1979, $\underline{87}, 701-718$.

Germany, J. David and Srivastava S., "Empirical Estimates of Unanticipated Policy: Issues in Stability and Identification," unpublished paper, MIT, December 1979.

Goldfeld, Steven M. and Quandt, Richard E., "Some Tests for Homoscedasticity," Journal of the American Statistical Association, 1965, 60, 538-547.

Gordon, Robert J., "New Evidence that Fully Anticipated Monetary Changes Influence Real Output After A11," Discussion Paper No. 368, The Center for Mathematical Studies in Economics and Management Science, Northwestern University, March 1979.

Granger, Clive W. J., "Investigating Causal Relations by Econometric Models and Cross-spectral Methods," Econometrica, July 1969, 37, 424-438. 
and Newbold, Pau1, "Spurious Regressions in Econometrics," Journal of Econometrics, 1974, 2, 111-120.

Grossman, Jean, "Nominal Demand Policy and Short-run Fluctuations in Unemployment and Prices in the United States," Journal of Political Economy, October 1979, 87, 1063-1085.

Leiderman, Leonardo, "Macroeconometric Testing of the Rational Expectations and Structural Neutrality Hypothesis for the United States," Journal of Monetary Economics, January 1980, $\underline{6}, 69-82$.

Ljung, C. M. and Box, George E. P., "On a Measure of Lack of Fit in Time Series Models," Biometrika, 65, 297-303.

Lucas, Robert E., Jr., "Some International Evidence on Output-Inflation Tradeoffs," American Economic Review, June 1973, 63, 326-324.

Mishkin, Frederic S., "Does Anticipated Monetary Policy Matter? An Econometric Investigation," April 1981, forthcoming in the Journal of Political Economy.

Modigliani, Franco, "The Monetarist Controversy, or Should We Forsake Stabilization Policies?" American Economic Review, March 1977, 67, 1-19. Sargent, Thomas J. (1976a), "A Classical Macroeconomic Model for the United States," Journal of Political Economy, April 1976, 84, 207-237. (1976b), "The Observational Equivalence of Natural and Unnatural

Rate Theories of Macroeconomics," Journal of Political Economy, June 1976 , 84, 631-640. and Wallace, Neil, "Rational Expectations, the Optimal Monetary Instrument and the Optimal Money Supply Rule," Journal of Political Economy, October 1975, 83, 241-254.

Small, David H., "Unanticipated Money Growth and Unemployment in the United States: Comment," American Economic Review, December 1979, 69, 996-1003. 